African Crop Science Journal by African Crop Science Society is licensed under a Creative Commons Attribution 3.0 Uganda License. Based on a work at www.ajol.info/ and www.bioline.org.br/cs DOI: https://dx.doi.org/10.4314/acsj.v29i2.9

\title{
STAY GREEN PHYSIOLOGICAL CAPACITY OF DROUGHT TOLERANT MAIZE INBRED LINES
}

\author{
G.T. EPAKU, P. RUBAIHAYO, F. KAGODA', K.D. BOMET ${ }^{2}$, A. BADJI, I. CHAPU \\ and G. OGWAL ${ }^{2}$ \\ School of Agricultural Sciences, Makerere University, P. O. Box 7062, Kampala, Uganda \\ 'Buginyanya Zonal Agricultural Research and Development Institute, P. O. Box 1356, \\ Mbale, Uganda \\ ${ }^{2}$ National Crops Resources Research Institute, P. O. Box 7084, Kampala, Uganda \\ Corresponding author: epaku.terry2@gmail.com
}

(Received 7 April 2021; accepted 17 May 2021)

\begin{abstract}
Stay green is the ability of a plant to maintain photosynthetically functional green leaf area for longer periods, even under excessive water stress. This study was done to establish the physiological capacity of Ugandan drought tolerant maize inbred lines to stay green under water shortage conditions using various stay green physiological determinants. Seventy-six maize inbred lines characterised for drought tolerance by CIMMYT, were planted under a rain out shelter, with a well-watered control (WW) and excessive water-stress treatments applied at six weeks after planting (6 WAP) and eight weeks after planting ( $8 \mathrm{WAP}$ ). The most maintained stay green physiological determinants under excessive water-stress were non-photosynthetic quench (NPQt) and leaf pigmentation per unit leaf area (RC: LAUG) with inbred lines CELQ15028 and CELQ15022 showing the highest maintenance for the two parameters, respectively. The highest level of variation for quantum yield of photosystem II activity (Phi2) and NPQt among inbred lines was at 40 and 60 days after flowering, respectively. Phi2 was negatively correlated to NPQt but positively correlated to the linear electron flow (LEF); while NPQt had a significantly negative correlation with LEF. This study established that these drought tolerant maize inbred lines have moderate stay green physiological capacity, with inbred line CEL15027 performing the best.
\end{abstract}

Key Words: Photosynthesis, pigmentation, water-stress, Zea mayz

\section{RÉSUMÉ}

Le retard de sénescence du feuillage ("stay green") est la capacité d'une plante à maintenir une surface foliaire verte photosynthétiquement fonctionnelle pendant de plus longues périodes, même en cas de stress hydrique excessif. Cette étude a été réalisée pour établir la capacité physiologique des lignées consanguines de maïs ougandaises tolérantes à la sécheresse à retard de sénescence du feuillage ("stay green") dans des conditions de pénurie d'eau en utilisant divers déterminants 
physiologiques de retard de sénescence du feuillage ("stay green"). Soixante-seize lignées consanguines de maïs caractérisées pour la tolérance à la sécheresse par le CIMMYT ont été plantées sous un abri anti-pluie, avec un contrôle bien arrosé (WW) et des traitements contre le stress hydrique excessif appliqués six semaines après la plantation (6 WAP) et huit semaines après la plantation. ( $8 \mathrm{WAP}$ ). Les déterminants physiologiques verts de séjour les plus maintenus sous un stress hydrique excessif étaient la trempe non photosynthétique (NPQt) et la pigmentation des feuilles par unité de surface foliaire (RC: LAUG) avec les lignées consanguines CELQ15028 et CELQ15022 présentant le maintien le plus élevé pour les deux paramètres respectivement. Le niveau de variation le plus élevé du rendement quantique de l'activité du photosystème II (Phi2) et du NPQt parmi les lignées consanguines était respectivement à 40 et 60 jours après la floraison. Phi2 était corrélé négativement au NPQt mais positivement corrélé au flux d'électrons linéaire (LEF) tandis que NPQt avait une corrélation significativement négative avec le LEF. Cette étude a établi que ces lignées consanguines de maïs tolérantes à la sécheresse avaient une capacité physiologique à retard de sénescence du feuillage ("stay green") modérée, la lignée consanguine CEL15027 a mieux fonctionné.

Mots Clés: Photosynthèse, pigmentation, stress hydrique, Zea mayz

\section{INTRODUCTION}

Establishment of the level of resilience inbred line has towards water-deprivation is important for plant breeders to make selections among populations to advance for hybrid development, targeting drought prone environments. This involves composite sourcing of germplasm and its subsequent phenotypic screening for drought tolerance attributes such as leaf rolling, anthesis-silking interval and the stay green trait (Edmeades $e t$ al., 1996). Previous studies on the stay green trait have largely relied on visual scoring of genotypes for their relative pigmentation, being easy and quick to perform in the field, and obviously important for screening large numbers of progenies (Almeida et al., 2014). A scale ranging from 1-10 as described by Walulu et al. (1994) is usually used basing on the estimated proportion of leaf death of normal sized leaves; where $1=$ zero to $10 \%, 2=11$ to $20 \%,,$, and $10=90$ to $100 \%$ leaf death. Other scholars such as Xu et al. (2000) modified this method to a $1-5$ scale with 1 indicating essentially no leaf death and 5 corresponding to complete plant death of leaves and stems. Bekavac et al., (2008) further modified this method by outlining the need to score for stay green at the base of the flag leaf and third leaf since senescence progressed from the tip towards the base of the leaf. These contributions have together formed the basis for stay green scoring in drought tolerance studies for various crops inclusive of maize (Wang et al., 2012).

Whereas Wanous et al. (1991) reported that visual green leaf area ratings were a reliable indicator of stay green, since they correlate well $\left(r=0.93^{* *}\right)$ with percentage green leaf area obtained by actual measurements of the leaf, Borrell et al. (2008) noted that these methods have some limitations such as individual biases and differences in ratings among observers. These shortcomings adversely affect the quality of results obtained and have, hence necessitated the development and use of more precise methods of scoring for stay green. Studies such as that by Xu $e t$ al. (2000) made use of fluorescent methods, alongside visual rating, where a Minolta chlorophyll meter SPAD-502 (Inoue et al., 1988) was used to score for chlorophyll content. These fluorescent methods are not only indications of leaf pigmentation like the visual ratings, but also measure how physiologically functional the pigmentation of the plant is (Spano et al., 2003). In this way, breeders and other scientists that intend to make use of such germplasm are able to 
effectively select for those that not only look green perse; but continue to function photosynthetically under such extreme water stress conditions. A case in point is the study by Yoo et al. (2007), that measured photosynthetic activity in rice with a portable PAM2000 chlorophyll fluorometer (Schroeter et al., 1992) and reported that the pigmentation of the leaves was not a direct indication of how photosynthetically active they were, a condition known as cosmetic stay green.

More precise fluorescent methods that measure the plant's photosynthetic ability and can, thus be used as stay green physiological capacity determinants under water-stress have been developed by photosynq (Kuhlgert et al., 2016). These include quantum yield of photosystem II activity (Phi2), which is the percentage of incoming light that goes into photosynthetic processes, since photosystem II is where most light energy is converted into food; and non-photosynthetic quench (NPQt) which is the amount of light turned into heat and dissipated by the plant to avoid damage to photosynthetic apparatus. Additional to these is the linear electron flow (LEF), which is the measure of how fast electrons move between photosystem I and photosystem II. Ideally, a functionally stay green plant would be one that can maintain average photosynthetic activity (Phi2) while protecting its photosynthetic apparatus (NPQt) for a longer period after physiological maturity. Such a genotype will typically exhibit a higher than average LEF under water-stress, indicating how fast electrons are moving between photosystem I and II for photosynthesis to commence. The objective of this study, therefore, was to determine the physiological capacity of Uganda's drought tolerant maize inbred lines to stay green under excessive water-stress using fluorescently measured physiological stay green determinants.

\section{MATERIALS AND METHODS}

This study was carried out at the National Crops Resources Research Institute
(NaCRRI), Namulonge in Uganda under a rainout shelter. Namulonge is located in the Lake Victoria crescent area at $0.5288^{\circ} \mathrm{N}, 32.6123$ ${ }^{\circ} \mathrm{E}$, at an altitude of $1204 \mathrm{~m}$ (Otim et al., 2018). The area had a mean temperature of $21.1^{\circ} \mathrm{C}$ during the period of study (Uganda National Meteorological Authority, 2019).

The study used 76 maize inbred lines from Kenya and Ethiopia (Table 1), with good drought tolerance attributes, as described by the International Maize and Wheat Improvement Centre (CIMMYT). The experiment comprised of a well-watered (WW) treatment and two water-deprived treatments that were applied at six weeks after planting (6 WAP) and at eight weeks after planting (8 WAP). The potting mixture for the wellwatered treatment was maintained at a water potential between 3-6 centibars; while that for the water-deprived treatments was maintained at a water potential between 15- 20 centibars using a tensiometer (Zaidi et al., 2015). This procedure involved measuring soil moisture at 10,20 and $30 \mathrm{~cm}$ three times every seven days to determine how much water should be added in order to maintain the required water potential for each treatment. Nitrogen, phosphorus and potassium tests carried out on the potting mixture before planting showed the nutrients to be at moderate quantities in the soil. Thus, NPK fertiliser (17:17:17) was applied at a rate of $12 \mathrm{~g}$ per pot twice; first at planting and when the plants were $65 \mathrm{~cm}$ high, by side dressing within the pot.

For each entry, four plants were raised in a randomised complete block design with a split plot arrangement consisting of three main treatments (WW, 6 WAP and 8 WAP), each treatment having two replications, and five critical senescence measurement points $(20$, 40,50 and 60 days after flowering) as the subplot treatments. Three seeds were planted per pot and later thinned to one. The photosynthetically active radiation (PAR) under the rain-out shelter was 450-570 nm supplied by sunlight with a 12 hour light period; ambient temperatures in the shelter were $25-30{ }^{\circ} \mathrm{C}$ and relative atmospheric humidity $30-60 \%$ as 
TABLE 1. Overall performance and ranking of inbred lines for the stay green physiological determinants inclusive of quantum yield of photosystem II $\stackrel{\omega}{\vec{N}}$ activity (Phi2), Linear electron flow (LEF), Non-photosynthetic quench (NPQt) and relative chlorophyll to leaf area under green ratio (RC: LAUG)

\begin{tabular}{|c|c|c|c|c|c|c|c|c|c|c|}
\hline Inbred line & Phi2 & Rank & LEF & Rank & NPQt & Rank & RC: LAUG & Rank & Overall rank & Position \\
\hline CELQ15027 & 0.35 & 34 & 44.71 & 16 & 14.61 & 7 & 2671.37 & 3 & 15.00 & 1 \\
\hline CELQ15034 & 0.36 & 26 & 37.54 & 46 & 99.99 & 2 & 2137.25 & 8 & 20.50 & 2 \\
\hline CKL 14531 & 0.33 & 54 & 45.20 & 10 & 12.94 & 14 & 1825.81 & 13 & 22.75 & 3 \\
\hline CELQ15018 & 0.35 & 28 & 44.35 & 17 & 6.47 & 45 & 2286.31 & 5 & 23.75 & 4 \\
\hline CELQ15046 & 0.44 & 2 & 47.51 & 4 & 3.34 & 71 & 1643.10 & 20 & 24.25 & 5 \\
\hline CELQ15057 & 0.35 & 35 & 41.58 & 28 & 13.09 & 13 & 1580.33 & 22 & 24.50 & 6 \\
\hline CELQ15049 & 0.35 & 30 & 40.02 & 37 & 9.19 & 33 & 2589.62 & 4 & 26.00 & 7 \\
\hline CELQ15005 & 0.38 & 14 & 42.28 & 25 & 6.12 & 48 & 1689.39 & 18 & 26.25 & 8 \\
\hline CELQ15028 & 0.41 & 7 & 39.87 & 39 & 170.73 & 1 & 684.46 & 58 & 26.25 & 8 \\
\hline CKLT 10344 & 0.32 & 61 & 49.20 & 3 & 8.37 & 36 & 2192.35 & 6 & 26.50 & 10 \\
\hline CELQ15040 & 0.39 & 9 & 44.24 & 18 & 3.79 & 64 & 1764.20 & 16 & 26.75 & 11 \\
\hline CELQ15003 & 0.39 & 12 & 40.09 & 36 & 6.15 & 47 & 1812.97 & 15 & 27.50 & 12 \\
\hline CKLMARS 10022 & 0.43 & 3 & 40.35 & 34 & 2.51 & 73 & 2866.61 & 2 & 28.00 & 13 \\
\hline CELQ15045 & 0.34 & 46 & 42.15 & 26 & 11.48 & 18 & 1553.92 & 23 & 28.25 & 14 \\
\hline CELQ15007 & 0.42 & 5 & 46.47 & 7 & 3.42 & 69 & 962.31 & 34 & 28.75 & 15 \\
\hline CELQ15019 & 0.35 & 36 & 47.13 & 5 & 8.62 & 34 & 753.13 & 44 & 29.75 & 16 \\
\hline CELQ15013 & 0.35 & 32 & 45.32 & 9 & 5.24 & 51 & 1191.19 & 28 & 30.00 & 17 \\
\hline CELQ15020 & 0.36 & 25 & 45.02 & 11 & 5.28 & 50 & 938.38 & 36 & 30.50 & 18 \\
\hline CKLT 10028 & 0.37 & 22 & 40.36 & 33 & 10.09 & 28 & 834.64 & 39 & 30.50 & 18 \\
\hline CELQ15021 & 0.42 & 6 & 40.51 & 32 & 4.35 & 61 & 1234.23 & 27 & 31.50 & 20 \\
\hline CKDHL 1700972 & 0.38 & 13 & 38.59 & 45 & 12.29 & 16 & 702.90 & 52 & 31.50 & 20 \\
\hline CELQ15052 & 0.34 & 48 & 43.58 & 20 & 11.31 & 19 & 782.29 & 40 & 31.75 & 22 \\
\hline CELQ15010 & 0.37 & 19 & 46.02 & 8 & 4.79 & 56 & 751.58 & 45 & 32.00 & 23 \\
\hline CELQ15036 & 0.41 & 8 & 46.85 & 6 & 2.37 & 74 & 758.09 & 42 & 32.50 & 24 \\
\hline CKLT 10348 & 0.34 & 49 & 39.57 & 40 & 9.40 & 32 & 2094.11 & 9 & 32.50 & 24 \\
\hline CELQ15059 & 0.36 & 23 & 40.85 & 31 & 4.24 & 63 & 1817.84 & 14 & 32.75 & 26 \\
\hline CELQ15053 & 0.39 & 10 & 32.92 & 68 & 9.50 & 31 & 1495.20 & 24 & 33.25 & 27 \\
\hline
\end{tabular}


TABLE 1. Contd.

\begin{tabular}{|c|c|c|c|c|c|c|c|c|c|c|}
\hline Inbred line & Phi2 & Rank & LEF & Rank & NPQt & Rank & RC: LAUG & Rank & Overall rank & Position \\
\hline CELQ15056 & 0.37 & 16 & 39.11 & 41 & 10.73 & 23 & 692.78 & 55 & 33.75 & 28 \\
\hline CELQ15055 & 0.34 & 47 & 44.83 & 14 & 2.55 & 72 & 2152.77 & 7 & 35.00 & 29 \\
\hline CKSBL 10008 & 0.32 & 65 & 36.53 & 52 & 13.44 & 11 & 1864.93 & 12 & 35.00 & 30 \\
\hline CELQ15022 & 0.28 & 74 & 49.81 & 2 & 3.69 & 65 & 3112.31 & 1 & 35.50 & 31 \\
\hline CELQ15006 & 0.35 & 31 & 42.00 & 27 & 7.91 & 38 & 707.73 & 50 & 36.50 & 32 \\
\hline CKDHL 153508 & 0.36 & 24 & 43.89 & 19 & 6.66 & 44 & 675.24 & 59 & 36.50 & 32 \\
\hline CKDHL 1701655 & 0.35 & 41 & 42.54 & 23 & 6.42 & 46 & 871.35 & 37 & 36.75 & 34 \\
\hline CELQ15016 & 0.36 & 27 & 40.93 & 29 & 9.76 & 30 & 635.66 & 62 & 37.00 & 35 \\
\hline CKDHL 1700954 & 0.45 & 1 & 44.91 & 13 & 1.92 & 76 & 663.49 & 60 & 37.50 & 36 \\
\hline CELQ15041 & 0.34 & 45 & 52.62 & 1 & 2.05 & 75 & 1100.55 & 30 & 37.75 & 37 \\
\hline CELQ15008 & 0.33 & 56 & 35.94 & 54 & 16.39 & 5 & 857.94 & 38 & 38.25 & 38 \\
\hline CELQ15017 & 0.39 & 11 & 32.23 & 69 & 4.26 & 62 & 1876.14 & 11 & 38.25 & 38 \\
\hline CELQ15012 & 0.35 & 38 & 44.98 & 12 & 7.84 & 39 & 607.80 & 66 & 38.75 & 40 \\
\hline CELQ15014 & 0.35 & 33 & 34.56 & 61 & 10.19 & 27 & 947.21 & 35 & 39.00 & 41 \\
\hline CELQ15025 & 0.35 & 43 & 35.09 & 59 & 8.13 & 37 & 1709.23 & 17 & 39.00 & 41 \\
\hline CKDHL 120773 & 0.35 & 29 & 33.96 & 65 & 13.38 & 12 & 694.38 & 53 & 39.75 & 43 \\
\hline CKL 172720 & 0.37 & 17 & 33.97 & 64 & 4.64 & 59 & 1652.93 & 19 & 39.75 & 43 \\
\hline CELQ15048 & 0.37 & 21 & 39.92 & 38 & 4.89 & 55 & 734.13 & 48 & 40.50 & 45 \\
\hline CELQ15001 & 0.32 & 64 & 33.15 & 66 & 14.37 & 9 & 1460.29 & 25 & 41.00 & 46 \\
\hline CELQ15002 & 0.31 & 69 & 35.91 & 55 & 14.47 & 8 & 1012.28 & 32 & 41.00 & 46 \\
\hline CELQ15037 & 0.38 & 15 & 35.66 & 57 & 10.68 & 24 & 594.90 & 69 & 41.25 & 48 \\
\hline CELQ15042 & 0.43 & 4 & 40.91 & 30 & 3.43 & 68 & 596.63 & 67 & 42.25 & 49 \\
\hline CELQ15015 & 0.33 & 58 & 39.08 & 42 & 4.38 & 60 & 1943.63 & 10 & 42.50 & 50 \\
\hline CELQ15054 & 0.35 & 39 & 40.10 & 35 & 3.39 & 70 & 1243.68 & 26 & 42.50 & 50 \\
\hline CELQ15026 & 0.34 & 52 & 31.78 & 71 & 12.53 & 15 & 970.72 & 33 & 42.75 & 52 \\
\hline CKL 15325 & 0.35 & 40 & 42.30 & 24 & 5.22 & 52 & 692.37 & 56 & 43.00 & 53 \\
\hline CELQ15009 & 0.37 & 20 & 37.13 & 49 & 4.67 & 58 & 735.90 & 47 & 43.50 & 54 \\
\hline CELQ15058 & 0.35 & 42 & 37.47 & 47 & 9.98 & 29 & 686.36 & 57 & 43.75 & 55 \\
\hline
\end{tabular}


TABLE 1. Contd.

\begin{tabular}{|c|c|c|c|c|c|c|c|c|c|c|}
\hline Inbred line & Phi2 & Rank & LEF & Rank & NPQt & Rank & RC: LAUG & Rank & Overall rank & Position \\
\hline CELQ15032 & 0.33 & 55 & 32.95 & 67 & 10.54 & 26 & 1158.38 & 29 & 44.25 & 56 \\
\hline CELQ15011 & 0.35 & 44 & 43.16 & 21 & 3.44 & 67 & 736.88 & 46 & 44.50 & 57 \\
\hline CELQ15044 & 0.34 & 51 & 38.77 & 43 & 6.88 & 42 & 756.41 & 43 & 44.75 & 58 \\
\hline CELQ15030 & 0.34 & 50 & 34.06 & 63 & 7.60 & 40 & 1023.77 & 31 & 46.00 & 59 \\
\hline CELQ15029 & 0.32 & 63 & 42.62 & 22 & 5.70 & 49 & 706.03 & 51 & 46.25 & 60 \\
\hline CELQ15024 & 0.37 & 18 & 36.71 & 51 & 5.04 & 53 & 595.28 & 68 & 47.50 & 61 \\
\hline CKL 14546 & 0.32 & 59 & 34.83 & 60 & 35.22 & 3 & 559.76 & 72 & 48.50 & 62 \\
\hline CELQ15033 & 0.34 & 53 & 35.95 & 53 & 10.56 & 25 & 618.62 & 65 & 49.00 & 63 \\
\hline CELQ15039 & 0.35 & 37 & 34.35 & 62 & 10.87 & 22 & 474.83 & 76 & 49.25 & 64 \\
\hline CELQ15038 & 0.31 & 66 & 35.55 & 58 & 8.44 & 35 & 773.38 & 41 & 50.00 & 65 \\
\hline CELQ15023 & 0.32 & 62 & 44.80 & 15 & 4.93 & 54 & 592.64 & 70 & 50.25 & 66 \\
\hline CELQ15004 & 0.31 & 71 & 37.02 & 50 & 11.26 & 21 & 649.60 & 61 & 50.75 & 67 \\
\hline CELQ15050 & 0.31 & 67 & 38.69 & 44 & 7.17 & 41 & 694.06 & 54 & 51.50 & 68 \\
\hline CELQ15047 & 0.32 & 60 & 32.22 & 70 & 14.92 & 6 & 585.70 & 71 & 51.75 & 69 \\
\hline CELQ15031 & 0.31 & 68 & 37.41 & 48 & 11.30 & 20 & 506.05 & 75 & 52.75 & 70 \\
\hline CKDHL 1700970 & 0.33 & 57 & 35.78 & 56 & 6.70 & 43 & 629.28 & 64 & 55.00 & 71 \\
\hline CKDHL 1701632 & 0.31 & 70 & 29.37 & 72 & 11.66 & 17 & 632.78 & 63 & 55.50 & 72 \\
\hline CELQ15035 & 0.27 & 75 & 27.02 & 73 & 26.92 & 4 & 514.48 & 74 & 56.50 & 72 \\
\hline CELQ15051 & 0.29 & 72 & 26.19 & 74 & 13.96 & 10 & 557.55 & 73 & 57.25 & 74 \\
\hline CKL 15645 & 0.29 & 73 & 19.69 & 76 & 3.60 & 66 & 1611.85 & 21 & 59.00 & 75 \\
\hline CELQ15043 & 0.24 & 76 & 24.21 & 75 & 4.69 & 57 & 731.43 & 49 & 64.25 & 76 \\
\hline LSD & 0.19 & & 17.75 & & 16.58 & & 658.50 & & & \\
\hline SEM & 0.08 & & 6.30 & & 5.88 & & 233.80 & & & \\
\hline
\end{tabular}

0
0
0

LSD = Least significant difference; SEM = standard error of the mean 
measured with a multi-spectrophotometer (Kuhlgert et al., 2016).

Data collection. Data were collected on Phi2, LEF, NPQt and relative chlorophyll (RC) using a multi-spectrophotometer operating on photosynq version v.10 (Kuhlgert et al., 2016) at six weeks after emergence of the crop, and then at 20, 40, 50 and 60 days after flowering (Zheng et al., 2009). This was done at the base of the leaf lamina of the second and fourth leaves from the top of the plant for three plants per entry and their respective averages computed. For leaf area under green (LAUG), one sided green leaf area of each genotype was measured by multiplying the length with the widest width of the longest green leaf per genotype, followed by dividing this result with the ground area occupied by each genotype (Wang et al., 2012). A ratio of RC to LAUG was then computed to obtain RC: LAUG.

Data processing and analysis. Data collected were subjected to the general analysis of variance (ANOVA) for randomised complete block design with split plot arrangement, using GenStat Software $18^{\text {th }}$ edition. Means for the treatments were separated using Fisher's Least Significant Difference procedure at $5 \%$ level of significance. The response to water deprivation across days after flowering was used to rank the overall performance of the genotypes, using the mean rank of all parameters from the expression (mean value of the respective parameter measured in the stressed plants/mean value of this parameter measured in the control plants) as described by Hola et al. (2010).

\section{RESULTS}

The results for the overall performance and ranking of the inbred lines for the stay green physiological capacity determinants are shown in Table 1. Inbred line CELQ15022 showed the highest mean RC: LAUG; while CELQ15039 showed the lowest.
CKDHL1700954 had the highest mean Phi2; while CELQ15043 had the lowest. CELQ15028 had the highest mean NPQt; while CELQ1700954 had the lowest. CELQ15041 had the highest mean LEF; while CELQ15045 had the lowest. Inbred lines CELQ15022 and CELQ15049 showed high maintenance of RC: LAUG under water deprivation, but with comparatively low Phi2 values in these conditions. Inbred line CELQ15046, despite having a low NPQt capacity, had high capacities of both Phi2 and LEF, making up for its high overall performance. Inbred line CKDHL1700954 had the highest mean Phi2, but with the lowest NPQt. Inbred line CELQ15027 showed the highest mean performance for all parameters while CELQ15043 showed the lowest. Overall, the five best performing inbred lines were CELQ15027, CELQ15034, CELQ15031, CELQ15018 and CELQ15046 while the least performing were CELQ15043 and CELQ15045.

There was a highly significant $(\mathrm{P}<0.01)$ variation for Phi2 and LEF among all inbred lines under the water deprivation treatments (Table 2). RC: LAUG was only significantly $(\mathrm{P}<0.01)$ different among all inbred lines under the 8 WAP water deprivation treatment; while NPQt significantly $(\mathrm{P}<0.01)$ varied amongst inbred lines only under the WW treatment and the 6 WAP water deprivation treatment (Table 2).

Results for variation of parameters with days after flowering are presented in Table 3. The inbred lines generally showed the highest level of variation for Phi2 at 40 days after flowering (DAF) under all treatments. LEF variation among inbred lines was generally the highest under the WW, 6 WAP and 8 WAP treatments at 20, 40 and 50 DAF, respectively. For NPQt, variation among inbred lines was generally highest at $60 \mathrm{DAF}$ for all treatments. RC: LAUG on the other hand, generally varied most at 20, 40 and 50 DAF among inbred lines under the WW, 8 WAP and 6 WAP treatments, respectively. 
TABLE 2. Mean square analysis of variance among inbred lines for stay green physiological determinants inclusive of quantum yield of photosystem II activity (Phi2), Linear electron flow (LEF), Nonphotosynthetic quench (NPQt) and relative chlorophyll to leaf area under green ratio (RC: LAUG)

\begin{tabular}{|c|c|c|c|c|c|}
\hline Parameter & Source of variation & D.f. & WW & $6 \mathrm{WAP}$ & 8 WAP \\
\hline \multirow[t]{4}{*}{ RC:LAUG } & Inbred line & 75 & 109,512 & 188,436 & $114,950 * *$ \\
\hline & DAF & 3 & $1,475,642 * *$ & $2,261,975 * *$ & $1,523,122 * *$ \\
\hline & Inbred line*DAF & 222 & 65,319 & 104,554 & $105,918 * * *$ \\
\hline & Residual & 250 & 88,000 & 191,526 & 43,608 \\
\hline \multirow[t]{4}{*}{ NPQt } & Inbred line & 75 & $56.02 * *$ & $63.86^{* *}$ & 61.4 \\
\hline & DAF & 3 & $1,427.42 * *$ & $573.58 * *$ & $1,520.64 * *$ \\
\hline & Inbred line*DAF & 218 & $56.29 * *$ & $46.63^{*}$ & 60.81 \\
\hline & Residual & 256 & 24.94 & 37.18 & 53.68 \\
\hline \multirow[t]{4}{*}{ Phi2 } & Inbred line & 75 & 0.018 & $0.032 * *$ & $0.022 * *$ \\
\hline & $\mathrm{DAF}$ & 3 & $1.539 * *$ & $0.319 * *$ & $0.811 * *$ \\
\hline & Inbred line*DAF & 225 & 0.016 & 0.018 & $0.025^{* *}$ \\
\hline & Residual & 292 & 0.018 & 0.017 & 0.014 \\
\hline \multirow[t]{4}{*}{ LEF } & Inbred line & 75 & 853 & $943.3^{* *}$ & $483.9 * *$ \\
\hline & DAF & 3 & $64,024 * *$ & $3402.3 * *$ & $40,534.4 * *$ \\
\hline & Inbred line*DAF & 225 & 1,044 & 576.5 & $489.4 * *$ \\
\hline & Residual & 303 & 1,088 & 616.9 & 246.6 \\
\hline
\end{tabular}

${ }^{* *}$ significant at $1 \%$, *significant at $5 \%$, D.f = degree of freedom; DAF = days after flowering; $\mathrm{WW}=$ well-watered; $6 \mathrm{WAP}=$ six weeks after planting water-stress; $8 \mathrm{WAP}=$ eight weeks after planting water-stress

Phi2 was generally negatively correlated with NPQt, but positively correlated with LEF among all inbred lines (Table 4). NPQt also had a significantly $(\mathrm{P}<0.05)$ negative correlation with LEF among all inbred lines (Table 4).

\section{DISCUSSION}

The insignificant variation for RC: LAUG among the inbred lines under the WW treatment, with means peaking at $20 \mathrm{DAF}$ and being lowest at $60 \mathrm{DAF}$, was due to the progressive senescence of the plants. When the inbred lines were deprived of water at 6 WAP, their mean RC: LAUG continued to increase up to $50 \mathrm{DAF}$, beyond which it started falling. This was due to senescence owing to their failure to form reproductive organs that would otherwise hasten the senescence process, since they act as sinks for the assimilates that are mobilised from the senescing leaf tissue. Al-Naggar et al. (2011) reported that reduced turgor during initiation of reproductive growth leads to abortion of reproductive effort.

The plants stressed at $8 \mathrm{WAP}$ were able to pollinate and form some kernels; explaining why they showed significant differences among inbred lines for RC: LAUG at different DAF, since they had different sink capacities and gene actions controlling their rates of source depletion (Tenkouano et al., 1993). In fact, the inbred lines showed the highest mean RC: LAUG at 40 DAF, a period when physiological maturity peaks for majority of 
TABLE 3. Variation of stay green physiological determinants inclusive of quantum yield of photosystem II activity (Phi2), Linear electron flow (LEF), Non-photosynthetic quench (NPQt) and relative chlorophyll to leaf area under green ratio (RC: LAUG); with days after flowering

\begin{tabular}{|c|c|c|c|c|c|c|c|c|c|c|}
\hline \multirow[t]{2}{*}{ Parameter } & \multirow[t]{2}{*}{ DAF } & \multicolumn{3}{|c|}{ WW } & \multicolumn{3}{|c|}{6 WAP } & \multicolumn{3}{|c|}{8 WAP } \\
\hline & & Mean & LSD & S.E & Mean & LSD & S.E & Mean & LSD & S.E \\
\hline \multirow[t]{5}{*}{ RC:LAUG } & 20 & 716.5 & $\mathbf{b}$ & 19.59 & 731.6 & b & 18.59 & 586.8 & $\mathrm{a}$ & 15.9 \\
\hline & 40 & 714.4 & $\mathrm{~b}$ & 18.36 & 751.6 & b & 23.25 & 750.8 & $\mathrm{~b}$ & 19.74 \\
\hline & 50 & 704.2 & $\mathrm{a}$ & 25.85 & 779.9 & $\mathrm{~b}$ & 48.98 & 708.3 & $\mathrm{~b}$ & 22.6 \\
\hline & 60 & 514.7 & $\mathrm{~b}$ & 27.8 & 513.9 & $\mathrm{a}$ & 34.52 & 536.3 & $\mathrm{a}$ & 29.96 \\
\hline & GM & 663 & & & 685 & & & 646.2 & & \\
\hline \multirow[t]{5}{*}{ NPQt } & 20 & 0.905 & $\mathrm{a}$ & 0.0298 & 3.598 & $\mathrm{a}$ & 0.5624 & 2.138 & $\mathrm{a}$ & 0.0824 \\
\hline & 40 & 0.987 & $\mathrm{a}$ & 0.1167 & 4.784 & $\mathrm{a}$ & 0.2941 & 2.567 & $\mathrm{a}$ & 0.276 \\
\hline & 50 & 2.346 & $\mathrm{~b}$ & 0.9354 & 7.413 & $\mathrm{~b}$ & 0.6001 & 3.289 & $\mathrm{a}$ & 0.2266 \\
\hline & 60 & 4.335 & $\mathrm{c}$ & 0.4821 & 7.491 & $\mathrm{~b}$ & 0.6705 & 4.594 & $\mathrm{~b}$ & 1.3234 \\
\hline & GM & 3.15 & & & 5.84 & & & 3.22 & & \\
\hline \multirow[t]{5}{*}{ Phi2 } & 20 & 0.4827 & $\mathrm{~b}$ & 0.00675 & 0.2947 & $\mathrm{~b}$ & 0.00904 & 0.4014 & $\mathrm{c}$ & 0.0075 \\
\hline & 40 & 0.5338 & $\mathrm{c}$ & 0.00588 & 0.3334 & $\mathrm{c}$ & 0.01052 & 0.4116 & $\mathrm{c}$ & 0.01129 \\
\hline & 50 & 0.4126 & $\mathrm{a}$ & 0.01435 & 0.3284 & $\mathrm{c}$ & 0.01387 & 0.3704 & $\mathrm{~b}$ & 0.01046 \\
\hline & 60 & 0.4043 & $\mathrm{a}$ & 0.01301 & 0.2315 & $\mathrm{a}$ & 0.01214 & 0.254 & $\mathrm{a}$ & 0.01474 \\
\hline & GM & 0.433 & & & 0.297 & & & 0.359 & & \\
\hline \multirow[t]{5}{*}{ LEF } & 20 & 75.35 & $\mathrm{c}$ & 1.952 & 38.7 & $\mathrm{a}$ & 0.933 & 23.45 & $\mathrm{a}$ & 0.604 \\
\hline & 40 & 48 & b & 1.269 & 40.76 & $\mathrm{~b}$ & 1.297 & 28.13 & b & 1.983 \\
\hline & 50 & 33.54 & $\mathrm{a}$ & 1.902 & 39.29 & b & 2.945 & 57.66 & $\mathrm{c}$ & 1.877 \\
\hline & 60 & 30.33 & $\mathrm{a}$ & 4.284 & 30.32 & $\mathrm{a}$ & 2.447 & 24.2 & $\mathrm{a}$ & 1.45 \\
\hline & GM & 46.8 & & & 37.3 & & & 33.36 & & \\
\hline
\end{tabular}

$\mathrm{DAF}=$ days after flowering; $\mathrm{WW}=$ well-watered $6 \mathrm{WAP}=$ six weeks after planting water-stress; 8 WAP = eight weeks after planting water-stress; LSD = Least significant difference; S.E = Standard error; $\mathrm{GM}=$ Grand mean. Bold figures are the highest means per parameter, showing peaks for variation for the parameter between inbred lines under a treatment

TABLE 4. Correlation between stay green physiological determinants inclusive of quantum yield of photosystem II activity (Phi2), Linear electron flow (LEF), Non-photosynthetic quench (NPQt) and relative chlorophyll to leaf area under green ratio (RC: $\mathrm{LAUG})$

\begin{tabular}{lrrrr}
\hline & Phi2 & RC:LAUG & LEF & NPQt \\
\hline Phi2 & - & & & \\
RC:LAUG & 0.25 & - & & \\
LEF & $0.13^{*}$ & 0.12 & - & - \\
NPQt & $-0.03^{*}$ & -0.02 & $-0.02^{*}$ & - \\
\hline
\end{tabular}

$*$ significant at $5 \%$ and $* *$ significant at $1 \%$ 
the maize germplasm (Zheng et al., 2009). The inbred lines were in general, able to maintain high levels of leaf pigmentation, especially under drought stress, since their mean RC: LAUG at 60 DAF, under the 6 WAP had a close difference from that under the 8 WAP treatment which was higher when compared to that of the WW treatment. The generally higher RC: LAUG values under the water deprivation treatments, compared to the WW treatment, were in disagreement to the findings of previous studies such as that by Efeoglu $e t$ al. (2009), which reported a significant reduction in chlorophyll content $(\mathrm{a}, \mathrm{b}, \mathrm{a}+\mathrm{b})$ of all maize cultivars under water deprivation; suggesting the superior ability of these stay green inbred lines to maintain leaf pigmentation under water-stress. The highest level of variation for this trait among all inbred lines was generally recorded at 20DAF, 40DAF and 50 DAF under WW, 8 WAP and 6 WAP treatments, respectively, suggesting that these were the best times to assess inbred lines subjected to similar treatments for this parameter.

NPQt values for all the inbred lines under the WW treatment were comparatively lower than those in the water deprivation treatments (Table 3), an indication that the inbred lines were able to utilise most of the received light energy for photosynthesis in the absence of water deprivation, but dissipate off most of the light energy that would otherwise destroy the rather compromised photosynthetic apparatus under the water deprivation treatments. This is further supported by the higher mean values under the 6 WAP than the 8 WAP treatment, which indicate that the longer the inbred lines were subjected to waterstress, the more efficient they were at this physiological process. Efficient screening strategies for this parameter should, therefore, be designed such that they rely on longer periods of water deprivation to allow for observation of as much variation as possible between germplasm. The insignificance in variation for NPQt under the 8 WAP treatment could have been due to insufficient exposure to water stress to show differences in the abilities of these inbred lines to protect their photosynthetic apparatus (Sharp et al., 2004). These findings were similar to those by Souza et al. (2013) that reported no significant difference for NPQt between plants under water-stress, although their values were higher than those of the irrigated plants. The inbred lines exhibited the highest levels of variation for this trait at $60 \mathrm{DAF}$ under all treatments suggesting this as the best period to assess for this parameter under similar treatments (O'Neill et al., 2006).

In the WW treatment, mean Phi2 values for the inbred lines were highest at $40 \mathrm{DAF}$, which was the peak of physiological maturity (Zheng et al., 2009) and were lowest at 60 DAF due to progressive senescence. The plants had sufficient moisture and were able to effectively maintain their higher mean photosynthetic ability than their water deprived counterparts, even up to $60 \mathrm{DAF}$. The insignificant difference between Phi2 for the various inbred lines under the WW treatment was due to their possession of fully functional photosynthetic apparatus, owing to the low rates of accumulation of oxygen reactive species, resulting in a low degradation rate of photosystem II activation centres (Zodape $e t$ al., 2012).

Comparatively, Phi2 mean values for the inbred lines were lower in the two water deprivation treatments than in the WW treatment at all DAF, an observation which was in agreement with the findings by Carvalho et al. (2011) that reported that with decreasing relative water content of the soil, Phi2 fell from 0.82 to 0.6. Efeoglu et al. (2009) also studied this parameter on maize plants under various levels of water treatment and reported that it decreased significantly in response to water-stress in all cultivars.

Van Wijk et al. (1994) suggested that in addition to the greater degradation rate of photosystem II reaction centres due to accumulation of reactive oxygen species, these 
low values were probably due to a lower synthesis rate of the D1 protein, which Nishiyama et al. (2006) noted was essential for repair of photo-inactivated photosystem II complexes. Colom and Vazzana (2003) also suggested that a sustained decrease of Phi2 indicated the occurrence of photo-inhibitory damage where there was a deviation from the normal quick dis-assembly and replacement of photo- inhibited reaction centres. In addition to photo-inhibition, Lu and Zhang (2000) suggested that the decrease in the quantum efficiency of open reaction centres in the light could be interpreted to represent an NPQtrelated increase, which leads to heat emission lowering the trapping efficiency of open reaction centres. Therefore, the water-stressinduced increase of NPQt on the inbred lines in the study indicated that the water-stress led to a strong loss of photosynthetically active reaction centres which in-turn explained why mean Phi2 values for all the inbred lines at different DAF were higher under the 8 WAP water-stress treatment than in the 6 WAP water-stress treatment since inbred lines in the latter were exposed to water-stress for longer periods of time. Furthermore, the significant variation for Phi 2 among inbred lines under the water-stress treatments was an indication that these inbred lines had varying levels to remain functionally photosynthetic under different levels of water-stress, an attribute that could be exploited for crop improvement programs. The highest level of variation for this trait among inbred lines was recorded at 40 DAF under all treatments suggesting that this was the best time to assess inbred lines subjected to similar treatments (Zheng et al., 2009).

Water-stress results in stomatal closure due to an accumulation of abscisic acid in the leaves (Davies and Zhang, 1991). Whereas stomatal closure limited dehydration due to transpiration, thereby reducing the risk of xylem cavitation that could have compromised the survival of the maize plants ( $\mathrm{Li}$ et al., 2013), it depleted intercellular carbon dioxide leading to accumulation of energy-containing products of electron transport, buildup of free radicals, perturbation of light-harvesting complexes, and photoinhibition (Spano et al., 2003). The reduced uptake of carbon dioxide and, hence reduced photosystem activity under water-stress, led to a decrease in the demand for the products of photochemistry, inclusive of ATP and NADPH since the plants resorted to a less photosynthetically-active survival state (Li et al., 2013). The significant positive correlation between Phi2 and LEF was, therefore, due to the accumulation of the photochemistry products at the reaction centres which resulted in a reduction of the LEF between photosystem I and photosystem II, which in turn explains the resultant reduction in Phi2 since there was a decrease in the excitation energy trapping of photosystem II reaction centres (Efeoglu et al., 2009). The results showed the highest mean LEF values for the inbred lines in the WW treatment, with the highest value recorded at 20 DAF because the environment allowed for high transpiration rates, resulting from open stomata allowing the stay green inbred lines to take in carbon dioxide and remain photosynthetically functional (Sinsawat et al., 2004). The subsequent reduction in these values with increase in days after flowering was due to progressive senescence of the plants (Tesfaye et al., 2015).

The inbred lines under the water-stress treatments generally recorded lower LEF values, when compared with those under the WW treatment, due to the accumulation of photochemistry products at their reaction centres resulting from stomatal closure (Spano et al., 2003). These results were in agreement with those obtained for maize hybrids under adequate and water deficit conditions in a field study by O'Neill et al. (2006). LEF values under the 8 WAP treatment continued to rise and peaked at $50 \mathrm{DAF}$, unlike those under the 6 WAP treatment that peaked at $40 \mathrm{DAF}$ owing to the comparatively shorter period of stomatal closure under the former 
(Sinsawat et al., 2004). These findings, therefore, suggested that assessment of inbred lines for LEF should be made at 20,40 and 50 DAF for plants under similar water-treatments. The insignificant difference between the LEF values for the various inbred lines under the WW treatment was due to their possession of fully functional photosynthetic apparatus owing to the very low rates of stomatal closure, unlike in the water-stress treatments where stomatal closure resulted in significantly varying levels of LEF among inbred lines owing to their individual abilities to maintain functional photosystems.

The inbred lines showed similar responses against drought stress with low deviations from their performance under optimum conditions for all parameters. The performance of the inbred lines was based on the population average rather than the value of a standard/ reference genotype that would otherwise display this trait to a high degree (Bekavac et al., 2007). Apart from CELQ15046, the five best performing inbred lines were able to cope with water-stress by, among their many adaptations, up-regulating protective mechanisms such as increasing NPQt which protected reaction centres from overload of photochemical products. This in turn explains the significant negative correlation between NPQt and LEF reported in this study. Inbred line CELQ15046, however, despite having a low NPQt capacity, was able to maintain high levels of photosystem II activity and linear electron flow for a considerable period under water-stress, making up for its high overall performance. CKDHL1700954 had the highest mean Phi2, but with the lowest NPQt. This explained its rather average overall performance due to its low photosystem protection capacity under water-stress (Miao et al., 2004). On the other hand, CELQ15028 had the highest NPQt which translated into longer periods of protection of photosynthetic apparatus under water-stress that translated into a high overall Phi2 (Efeoglu et al., 2009). Whereas inbred lines CELQ15022 and CELQ15049 showed high maintenance RC: LAUG even under water-stress, this study established that they had comparatively low photosynthetic abilities under these conditions, suggesting that they are not-functionally stay green inbred lines (Yoo et al., 2007). The results of this study also suggested that inbred lines CELQ15043 and CEL15045 are the least overall water-stress tolerant when compared to the other inbred lines. These lines exhibited the lowest values for NPQt under water-stress indicating a lower efficiency in protecting their photosynthetic apparatus which resulted in very low Phi2 values (Souza et al., 2013).

\section{CONCLUSION}

This study established that Ugandan drought tolerant maize inbred lines have moderate stay green physiological capacity. Inbred lines CELQ15027, CELQ15034, CELQ15031, CELQ15018 and CELQ15046 were the overall best performing inbred lines. CKDHL1700954 could be used in backcrosses to specifically improve other genotypes for Phi2. CELQ15028 could be used in backcrosses to particularly improve other genotypes for protection of photosynthetic apparatus under water-stress. Selection for Phi2, LEF and NPQt could be made at the same time because of the significant correlation among the traits.

\section{ACKNOWLEDGEMENT}

This work was accomplished with financial support from the Regional Universities Forum for Capacity in Agriculture (RUFORUM) together with the World Bank through the African Centre of Excellence in Materials, Product Development and Nanotechnology (MAPRONANO ACE II).

\section{REFERENCES}

Almeida, G.D., Nair, S., Borém, A., Cairns, J., Trachsel, S., Ribaut, J. M. and Babu, R. 2014. Molecular mapping across three 
populations reveals a QTL hotspot region on chromosome 3 for secondary traits associated with drought tolerance in tropical maize. Molecular breeding 34(2):701-715.

Al-Naggar, A.M.M., Soliman, S.M. and Hashimi, M.N. 2011. Tolerance to drought at flowering stage of 28 maize hybrids and populations. Egypt Journal of Plant Breeding 15(1):69-87.

Bekavac, G., Purar, B. and Jockoviæ, Đ. 2008. Relationships between line per se and testcross performance for agronomic traits in two broad-based populations of maize. Euphytica 162(3):363-369.

Bekavac, G., Purar, B., Stojakoviæ, M., Jockoviæ, D., Ivanoviæ, M. and Nastasiæ, A. 2007. Genetic analysis of stay green trait in broad-based maize populations. Cereal Research Communications 35(1):31-41.

Borrell, A.K., Jordan, D., Mullet, J., Klein, P., Klein, R., Nguyen, H. and Henzell, B. 2008. Discovering stay green drought tolerance genes in sorghum: a multidisciplinary approach. Australian Agronomy Conference 14:21-25.

Carvalho, R.C., Cunha, A. and da Silva, J.M. 2011. Photosynthesis by six Portuguese maize cultivars during drought stress and recovery. Acta Physiologiae Plantarum 33(2):359-374.

Colom, M.R. and Vazzana, C. 2003. Photosynthesis and PSII functionality of drought-resistant and drought-sensitive weeping love-grass plants. Environmental and Experimental Botany 49(2):135-144.

Davies, W.J. and Zhang, J. 1991. Root signals and the regulation of growth and development of plants in drying soil. Annual Review of Plant Biology 42(1):5576.

Edmeades, G.O., Bolaños, J. and Chapman, S.C. 1996. Value of secondary traits in selecting for drought tolerance in tropical maize. In: Developing drought and low Ntolerant maize. Proceedings of a Symposium on March 25-29, 1996, CIMMYT, El Batan, Mexico. Edmeades, G.O., Banziger,
M., Mickelson, H.R. and Pena-Valdivia, C.B. (Eds.). D.F. CIMMYT/UNDP, Mexico. pp. 222-234.

Efeoðlu, B., Ekmekçi, Y.A. and Çiçek, N.U. 2009. Physiological responses of three maize cultivars to drought stress and recovery. South African Journal of Botany 75(1):34-42.

Holá, D., Benešová, M., Honnerová, J., Hnilièka, F., Rothová, O., Koèová, M. and Hnilièková, H. 2010. The evaluation of photosynthetic parameters in maize inbred lines subjected to water deficiency: Can these parameters be used for the prediction of performance of hybrid progeny? Photosynthetica 48(4):545-558.

Inoue, M., Taniguchi, N., Hata, Y., Hoda, T., Kudo, Y. and Ueda, H. 1988. U.S. Patent No. 4,728,978. Washington, DC: U.S. Patent and Trademark Office.

Kuhlgert, S., Austic, G., Zegarac, R., OseiBonsu, I., Hoh, D., Chilvers, M.I., Roth, M.G., Bi, K., TerAvest, D., Weebadde, P. and Kramer, D.M. 2016. MultispeQ Beta: A tool for large-scale plant phenotyping connected to the open PhotosynQ network. Royal Society Open Science 3(10): p.160592.

Li, Y.F., Wu, Y., Hernandez-Espinosa, N. and Peña, R.J. 2013. Heat and drought stress on durum wheat: Responses of genotypes, yield, and quality parameters. Journal of Cereal Science 57(3):398-404.

Lu, C.M. and Zhang, J.H. 2000. Photosystem II photochemistry and its sensitivity to heat stress in maize plants as affected by nitrogen deficiency. Journal of Plant Physiology 157(1):124-130.

Miao, Y. 2004. Targets of the WRKY53 transcription factor and its role during leaf senescence in Arabidopsis. Plant Molecular Biology 55.6:853-867.

Nishiyama, Y., Allakhverdiev, S.I. and Murata, N. 2006. A new paradigm for the action of reactive oxygen species in the photoinhibition of photosystem II. Biochimica 
et Biophysica Acta (BBA)-Bioenergetics 1757(7):742-749.

O’Neill, P.M., Shanahan, J.F. and Schepers, J.S. 2006. Use of chlorophyll fluorescence assessments to differentiate corn hybrid response to variable water conditions. Crop Science 46(2):681-687.

Otim, M.H., Tay, W.T., Walsh, T.K., Kanyesigye, D., Adumo, S., Abongosi, J., Ochen, S., Sserumaga, J., Alibu, S., Abalo, G. and Asea, G. 2018. Detection of sisterspecies in invasive populations of the fall armyworm Spodoptera frugiperda (Lepidoptera: Noctuidae) from Uganda. PloS One 13(4):p.e0194571.

Schroeter, B., Green, T.G. A., Seppelt, R.D. and Kappen, L. 1992. Monitoring photosynthetic activity of crustose lichens using a PAM-2000 fluorescence system. Oecologia 92(4):457-462.

Sharp, R.E., Poroyko, V., Hejlek, L.G., Spollen, W.G., Springer, G.K., Bohnert, H.J. and Nguyen, H.T. 2004. Root growth maintenance during water deficits: physiology to functional genomics. Journal of Experimental Botany 55(407):23432351.

Sinsawat, V., Leipner, J., Stamp, P. and Fracheboud, Y. 2004. Effect of heat stress on the photosynthetic apparatus in maize (Zea mays L.) grown at control or high temperature. Environmental and Experimental Botany 52(2):123-129.

Souza, T.C., de Castro, E.M., Magalhaes, P.C., Lino, L.D., Alves, E.T., de Albuquerque, P.E. 2013. Morphophysiology, morphoanatomy, and grain yield under field conditions for two maize hybrids with contrasting response to drought stress. Acta Physiologiae Plantarum 35(11): 3201-3211.

Spano, G., Di Fonzo, N., Perrotta, C., Platani, C., Ronga, G., Lawlor, D.W. and Shewry, P.R. 2003. Physiological characterization of 'stay green'mutants in durum wheat. Journal of Experimental Botany 54(386): 1415-1420.
Tenkouano, A., Miller, F.R., Frederiksen, R. A. and Rosenow, D. T. 1993. Genetics of nonsenescence and charcoal rot resistance in sorghum. Theoretical and Applied Genetics 85(5):644-648.

Tesfaye, K., Gbegbelegbe, S., Cairns, J.E., Shiferaw, B., Prasanna, B.M., Sonder, K. and Robertson, R. 2015. Maize systems under climate change in sub-Saharan Africa: Potential impacts on production and food security. International Journal of Climate Change Strategies and Management 7(3): 247-271.

Uganda National Meteorological Authority. August/ December 2019. https:// en.wikipedia.org/wiki/Uganda_National_ Meteorological_Authority Accessed on 27 April, 2019.

Van Wijk, K.J., Nilsson, L.O. and Styring, S. 1994. Synthesis of reaction center proteins and reactivation of redox components during repair of photosystem II after lightinduced inactivation. Journal of Biological Chemistry 269(45):28382-28392.

Walulu, R.S., Rosenow, D.T., Wester, D.B. and Nguyen, H.T. 1994. Inheritance of the stay green trait in sorghum. Crop Science 34(4):970-972.

Wang, A.Y., Li, Y. and Zhang, C.Q. 2012. QTL mapping for stay green in maize (Zea mays). Canadian Journal of Plant Science 92(2):249-256.

Wanous, M.K., Miller, F.R. and Rosenow, D.T. 1991. Evaluation of visual rating scales for green leaf retention in sorghum. Crop Science 31(6):1691-1694.

$\mathrm{Xu}$, W., Subudhi, P.K., Crasta, O.R., Rosenow, D.T., Mullet, J.E. and Nguyen, H.T. 2000. Molecular mapping of QTLs conferring stay green in grain sorghum (Sorghum bicolor L. Moench). Genome 43(3):461-469.

Yoo, S.C., Cho, S.H., Zhang, H., Paik, H.C., Lee, C.H., Li, J., Yoo, J.H., Koh, H.J., Seo, H.S. and Paek, N.C. 2007. Quantitative trait loci associated with functional stay-green SNU-SG1 in rice. Molecules \& Cells 
(Springer Science \& Business Media BV) 24(1).

Zaidi, P.H., Rashid, Z., Vinayan, M.T., Almeida, G.D., Phagna, R.K. and Babu, R. 2015. QTL mapping of agronomic waterlogging tolerance using recombinant inbred lines derived from tropical maize (Zea mays L.) germplasm. PLoS One 10(4):e0124350.

Zheng, H.J., Wu, A.Z., Zheng, C.C., Wang, Y.F., Cai, R., Shen, X.F. and Dong, S.T.
2009. QTL mapping of maize (Zea mays) stay green traits and their relationship to yield. Plant Breeding 128(1):54-62.

Zodape, S.T., Mukherjee, S., Reddy, M.P. and Chaudhary, D.R. 2012. Effect of Kappaphycus alvarezii (Doty) Doty ex silva. Extract on grain quality, yield and some yield components of wheat (Triticum aestivum L.). International Journal of Plant Production 3(2):97-101. 